\title{
Deciphering Brain Function by Miniaturized Fluorescence Microscopy in Freely Behaving Animals
}

\author{
Sarah Malvaut ${ }^{1,2+}$, Vlad-Stefan Constantinescu' ${ }^{1,2 t}$, Harold Dehez ${ }^{3}$, Sead Doric ${ }^{3}$ and \\ Armen Saghatelyan 1,2* \\ ${ }^{1}$ CERVO Brain Research Center, Quebec City, QC, Canada, ${ }^{2}$ Department of Psychiatry and Neuroscience, Universite Laval, \\ Quebec City, QC, Canada, ${ }^{3}$ Doric Lenses Inc., Quebec City, QC, Canada
}

OPEN ACCESS

Edited by:

João O. Malva,

University of Coimbra, Portugal

Reviewed by:

Daniel Benjamin Aharoni,

University of California, Los Angeles,

United States

Alberto L. Vazquez,

University of Pittsburgh, United States

*Correspondence:

Armen Saghatelyan

armen.saghatelyan@fmed.ulaval.ca; armen.saghatelyan@crulrg.ulaval.ca

${ }^{\dagger}$ These authors have contributed equally to this work

Specialty section:

This article was submitted to Brain Imaging Methods, a section of the journal

Frontiers in Neuroscience

Received: 20 April 2020

Accepted: 14 July 2020

Published: 11 August 2020

Citation:

Malvaut S, Constantinescu V-S, Dehez H, Doric S and Saghatelyan A (2020) Deciphering Brain Function by

Miniaturized Fluorescence

Microscopy in Freely Behaving

Animals. Front. Neurosci. 14:819.

doi: 10.3389/fnins.2020.00819
Animal behavior is regulated by environmental stimuli and is shaped by the activity of neural networks, underscoring the importance of assessing the morpho-functional properties of different populations of cells in freely behaving animals. In recent years, a number of optical tools have been developed to monitor and modulate neuronal and glial activity at the protein, cellular, or network level and have opened up new avenues for studying brain function in freely behaving animals. Tools such as genetically encoded sensors and actuators are now commonly used for studying brain activity and function through their expression in different neuronal ensembles. In parallel, microscopy has also made major progress over the last decades. The advent of miniature microscopes (mini-microscopes also called mini-endoscopes) has become a method of choice for studying brain activity at the cellular and network levels in different brain regions of freely behaving mice. This technique also allows for longitudinal investigations while animals carrying the microscope on their head are performing behavioral tasks. In this review, we will discuss mini-endoscopic imaging and the advantages that these devices offer to research. We will also discuss current limitations of and potential future improvements in mini-endoscopic imaging.

Keywords: miniature endoscopes, mini-endoscopic imaging, animal behavior, GRIN lenses, GCaMP, GECI, $\mathrm{Ca}^{2+}$ imaging

\section{INTRODUCTION}

Understanding how brain functions are shaped by experience and, in turn, how neural networks regulate animal behavior has always been of great interest to the scientific community as well as the general public. One of the long-term aims of neuroscience research is to understand how specific spatio-temporal activity patterns emerging from local neural networks regulate specific animal behaviors. Recording neural activity at the microcircuit level from distinct subsets of neurons and glia in freely behaving animals has thus become essential for studying how experience is represented and processed by the brain. The function of these networks can be interrogated using extracellular multi-electrode recordings (Nicolelis and Ribeiro, 2002), large-scale brain imaging techniques such as functional magnetic resonance imaging (fMRI), voltage-sensitive dye-based imaging, intrinsic optical signal imaging, and positron emission tomography (PET) (Grinvald et al., 1988; 
Shoham et al., 1999; Logothetis et al., 2002), or in vivo $\mathrm{Ca}^{2+}$ imaging using one- and two-photon mini-endoscopes (Dombeck et al., 2007; Kerr et al., 2007; Grewe and Helmchen, 2009). The technique of choice for these types of experiments has mostly involved taking electrophysiological recordings in either awake head-restrained or freely behaving rodents (Wilson and Mcnaughton, 1993; Houweling and Brecht, 2008; Harvey et al., 2009; Niell and Stryker, 2010). This approach has provided a great number of important insights into how neuronal ensembles orchestrate behavior such as the discovery of spatial representation by place and grid cells, for instance (O'keefe and Dostrovsky, 1971; Hafting et al., 2005). However, despite the tremendous value of this technique, the number of cells that can be recorded at a given time is limited by the small number of electrodes that can be used simultaneously. In theory, increasing the number of electrodes should make it possible to record electrophysiological activity in more cells, but the spacing between the electrodes is limited. Electrophysiological recordings also exclude electrically silent cells from the subsequent analysis of network dynamics (Shoham et al., 2006). To address some of these caveats, researchers can now take advantage of dense recordings using multi-tetrode arrays or silicone probes that make it possible to take recordings from large neuronal populations rather than from individual cells. Such large population-level recordings can be used to address questions that otherwise could not have been investigated using data from individual cell recordings (Csicsvari et al., 2003; Harris et al., 2003; Buzsaki, 2004; Dupret et al., 2010; Stensola et al., 2012). However, even with advances in electrophysiological recordings of large subsets of cells, there remain some important aspects that cannot be studied using such techniques. Although electrophysiology allows for distinct cell populations to be differentiated based on waveform shapes (Trainito et al., 2019), it is much more challenging to assess the individual contribution of each subset of recorded cells to the observed network dynamics. Recordings from subcellular structures such as dendrites can be also obtained in freely behaving mice using electrophysiological approaches (Moore et al., 2017). By taking advantage of the immune response that follows a tetrode implant, which allows a dendrite to get trapped between the tetrode tips and the glial encapsulation, it is possible to measure the dendritic membrane voltage in freely behaving rodents (Moore et al., 2017). This methodology could also provide important insights into the electrophysiological correlates of dendritic action potential integration, but has a low success rate and low yield.

The study of brain function has taken a step further with the advent of new optical tools designed to investigate neuronal activity at the protein, cellular, or network level. These include genetically encoded $\mathrm{Ca}^{2+}$ indicators (GECIs). $\mathrm{Ca}^{2+}$ is an important second messenger involved in the homeostasis of essentially all cells in the brain (Clapham, 1995; Berridge et al., 2000) and GECI-recorded $\mathrm{Ca}^{2+}$ fluctuations can be used to study the activity and coding of neural ensembles in basal conditions and in response to stimuli (Tian et al., 2012; Lin and Schnitzer, 2016). Many different versions of GECIs exist, and their repertoire and properties are constantly improving (Dana et al., 2016, 2019; Shen et al., 2020). The green and red $\mathrm{Ca}^{2+}$ indicators (GCaMP and RCaMP, respectively) are the most common (Lin and Schnitzer, 2016; Shen et al., 2020). More recently, a quadricolor GECI suite (XCaMP) (Inoue et al., 2019) and a near-infrared $\mathrm{Ca}^{2+}$ indicator (Qian et al., 2019) were designed to further expand the palette of GECIs and to study more complex neural dynamics. Using viral or transgenic labeling, GECIs can be expressed all over the brain or in specific neuronal/glial subtypes and are now widely used in the context of learning, memory formation, and plasticity (Jercog et al., 2016). They also allow for long-term investigations of brain activity for up to several weeks and even months (Jercog et al., 2016). In addition to GECIs, current efforts to develop genetically encoded voltage indicators (GEVIs) will eventually make it possible to monitor individual spikes during high-frequency trains of action potentials or subthreshold changes in the membrane potential in selected populations of cells (Bando et al., 2019). This will further increase the palette of functional assessments of neural networks during animal behavior. In addition to functional changes, several morphological modifications such as spine formation/elimination, the dynamics of glia processes, and microglia migration occur in response to environmental stimuli. Furthermore, several regions of the adult brain retain the capacity to renew their cellular populations during injury (Torper and Gotz, 2017) or under homeostatic conditions through adult neurogenesis (Gengatharan et al., 2016; Obernier and Alvarez-Buylla, 2019; Vicidomini et al., 2020). All these morphological changes can be also monitored in vivo using live imaging approaches (Berry and Nedivi, 2017; Pilz et al., 2018; Wallace et al., 2020).

In vivo imaging of morpho-functional changes in zebra fish larvae and nematodes has been performed in whole organisms (Ahrens et al., 2012; Nguyen et al., 2016). In rodents, in vivo imaging of a given brain region has traditionally been performed by two-photon microscopy in anesthetized or awake headrestrained animals performing specific behavioral tasks. While this allows for long-term and longitudinal recording of brain activity, it is limited to a restricted number of behavioral tasks and cannot be used to study deep brain structures unless the overlying brain regions are removed, which may affect cellular activity and animal behavior. The last two decades saw the advent of miniaturized fluorescent microscopes (also called minimicroscopes or mini-endoscopes) that enable in vivo recordings of brain structure and function of freely behaving animals to be taken at the cellular and network levels. These devices, which are similar to benchtop microscopes in their optical designs, contain miniaturized optical parts (mirrors, filters, or even a camera) and can be carried by animals that freely displace in an arena. Displays and recordings of acquired images are then computer assisted, allowing for the modulation of different parameters such as acquisition frame rate, exposure, and illumination power, without any additional manipulation of the recorded animal. Mini-endoscopes have evolved considerably in recent years since the first miniaturized versions were developed (Helmchen et al., 2001) and are still being refined and improved. They have helped provide answers to several unresolved questions regarding brain activity and structure. In this review, we will first present the various models of currently available mini-endoscopes and 
provide an overview of their specifications, advantages, and limitations. We will then discuss the in vivo applications of miniendoscopy and the limitations of existing devices as well as future avenues for improving mini-endoscopic microscopy.

\section{CURRENT STATE OF THE ART FOR RECORDING BRAIN ACTIVITY AND STRUCTURE USING MINI-ENDOSCOPES}

\section{One-Color Mini-Endoscopes}

The first versions of mini-endoscopes were based on twophoton excitation, and some microscope components such as lasers and photomultipliers (PMT) were converted to transmit the excitation light to the head of the animal or to collect emissions through optic fibers. These systems were used for imaging at the surface of the brain (Helmchen et al., 2001; Helmchen, 2002; Flusberg et al., 2005). They were bulky and heavy (25 g, $70 \mathrm{~mm}$ high), limiting applications involving naturalistic behavior. Also, the devices could not compensate very well for strong motion artifacts (Helmchen et al., 2001; Helmchen, 2002). Subsequent improvements led to the creation of lighter portable two-photon excitation microscopes (Gobel et al., 2004; Flusberg et al., 2008; Sawinski et al., 2009) that were used to image neural networks in freely moving mice and rats. A promising approach using a portable two-photon excitation-scanning microscope that weighs as little as $2 \mathrm{~g}$ was recently introduced to study activity in the entorhinal cortex of freely behaving mice (Zong et al., 2017; Rowland et al., 2018). These systems provide the obvious advantages of twophoton excitation microscopy such as a small excitation volume, increased tissue penetration, reduced phototoxicity, and the possibility of imaging subcellular structures. However, the low two-photon absorption cross-section also imposes high spatial (small focal spot) and temporal (short laser pulse) constraints on two-photon microscopy systems. To get sufficient excitation intensity at focus, it requires high numerical aperture diffractionlimited optics as well as expensive table-top femtosecond pulse lasers with proper dispersion compensation. Laser scanning twophoton microscopes should also be properly stabilized to avoid motion artifacts as the pixels of each image are not recorded simultaneously. It is thus more challenging to use two-photon excitation in a context of mini-endoscopes, suggesting that miniaturized epifluorescence microscopy tends to represent a simpler and more affordable method for imaging activity in neural networks at the cellular level, particularly in deep brain regions while animals are freely behaving.

Several groups have taken advantage of small optical rod lenses [gradient refractive index (GRIN) lenses] (Jung and Schnitzer, 2003; Levene et al., 2004) to build mini-endoscopes. These lenses have a short working distance and can be fixed either at the surface of the brain or inserted into deep brain regions to perform imaging in the superficial or deep brain regions, respectively (Helmchen et al., 2001; Helmchen, 2002; Flusberg et al., 2005). GRIN lenses, which can have different diameters and customizable lengths, have been used for in vivo imaging of previously unreachable deep brain structures such as the substantia nigra, the hypothalamus, the parabrachial nucleus, and the basal forebrain (Bocarsly et al., 2015; Fu et al., 2019; Patel et al., 2019). GRIN lenses are usually flat at the tip, making it possible to image cells just below the tip. However, they can also be coupled with a prism mirror allowing for "side-view" imaging. This configuration, in our experience, significantly reduces tissue damage and immune responses compared to blunt probes. In line with this, less tissue damage and better neuronal preservation is observed for well-sharpened and small tip angle silicone probes used for in vivo electrophysiological recordings (Edell et al., 1992). The GRIN coupled with a prism has been used for imaging neurons located in different cortical layers (Gulati et al., 2017).

Gradient refractive index implantation is minimally invasive, and the presence of the lens in an animal's brain does not alter the locomotion or behavior of the animal in selected tasks commonly used in neuroscience research (Lee et al., 2016), although this largely depends on the diameter and type of GRIN lens (Resendez et al., 2016). Larger diameter ( $1 \mathrm{~mm}$ ) GRIN lenses have been described as being more suitable for an implantation in superficial brain regions such as the cortex or the hippocampus, whereas smaller diameter GRINs are more suitable for deeper brain regions such as the hypothalamus or the ventral tegmental area (Resendez et al., 2016). Slow insertion of probes during implantation or using probes coupled with a prism can minimize possible compression of the brain, restricting it to the front of the GRIN and reducing possible damage (Edell et al., 1992; Levene et al., 2004). For deep brain region imaging, a track in the brain is often created using a sharp needle or blade. Brain tissue aspiration is also used in some cases (Resendez et al., 2016; Gulati et al., 2017; Gonzalez et al., 2019; De Groot et al., 2020). The inflammatory response resulting from implant insertion normally largely clears up after 4 weeks (Bocarsly et al., 2015), or less for sharp-ended implants (Edell et al., 1992; Turner et al., 1999). This observation highlights the need to start recording with miniature endoscopes several weeks post-implantation. A minimal period ranging from 2 to 4 weeks is required before acquiring data using GRIN lenses (Barbera et al., 2019; Fu et al., 2019; Gonzalez et al., 2019). To confirm the correct implantation of a GRIN lens, a post hoc analysis in post-mortem brain tissues can be used. This step makes it possible to adapt the stereotaxic coordinates used in different animals (Lee et al., 2016; Resendez et al., 2016). When viral vectors are injected in a defined brain region a few weeks before GRIN implantation, changes in background fluorescence may be also used to ascertain the correct positioning.

As for animals becoming habituated to the imaging device, it is common practice to try to reduce the weight of mini-endoscopes as much possible so as to not interfere with naturalistic behavior of the animals (Resendez et al., 2016). Chronic GRIN implants do not alter animal performance in standard behavioral procedures such as the rotarod test or the Morris water maze (Lee et al., 2016). However, no comparative studies have been reported with regard to the adaptation of animals to mini-endoscopes of different weights and configurations. Further behavioral investigations will be required to accurately evaluate the maximal weight that small rodents like mice can carry on their head without an impact on their behavior and to compare different 
mini-endoscopes, some of which are bulkier than others. Also, not all available versions of mini-endoscopes can reach very lateral or anterior brain regions such as the olfactory bulb. In fact, due to size constraints, placing a mini-endoscope in such regions could potentially alter the normal behavior of the animals or even their vision if placed too close to their eyes. Smaller footprint mini-endoscopes may help to resolve this issue.

An important step in the conception of mini-endoscopes is thus the miniaturization of microscope parts. Ghosh et al. (2011), in their first version of a fully miniaturized epifluorescence miniendoscope, replaced larger external light sources (e.g., Xenon lamps, mercury lamps, high power LEDs, and lasers) with smaller internal LEDs that are efficient and low-cost alternatives. This approach is now widely used in different open source miniendoscopes designed to image in freely behaving rodents or songbirds. These include the UCLA Miniscope (Cai et al., 2016), the National Institute of Drug Abuse MiniScope (Barbera et al., 2016), the Boston University FinchScope that was developed for imaging in songbirds (Liberti et al., 2017), and the University of Toronto CHEndoscope (Jacob et al., 2018). Although very practical in terms of cost, availability, and size, installing LEDs directly in the microscope body can have some drawbacks. Because of its location in the microscope body, maximum output power is limited in order to minimize potential excessive heat on the animal's head at higher powers normally used for optogenetic stimulations. To alleviate these issues, some commercial one-color mini-endoscopes can be connected to adjustable, exchangeable external light sources such as lasers, laser pumped incoherent sources (Ce:YAG), or LEDs using an optical fiber. However, this has the disadvantage of adding an extra optical fiber above the animal's head.

Mini-endoscopes also take advantage, in their design, of off-the-shelf miniature electronic components such as complementary metal oxide semiconductor (CMOS) sensors for image detection. These sensors support high acquisition frame rates (higher than $30 \mathrm{~Hz}$ ) and can, in some cases, be coupled to a microphone to record songbird vocalizations (Liberti et al., 2017). Improved versions of mini-endoscopes are currently available from commercial sources (Doric Lenses, Inscopix, and Neurescence) as well as open-source platforms (UCLA Miniscope, NINscope, and FinchScope).

It should be also mentioned that because of their miniaturization and their use in freely behaving animals, device failure may also occur. Unlike tabletop microscopy systems, miniaturized fluorescence microscopes are operated in challenging environments, with the animal moving in different directions and potentially applying some constraints on the microscope and optical fibers. Several approaches have been investigated to reduce the risks of experiment interruption due to microscope failure, including sturdier bodies in hard plastic (Cai et al., 2016) and metal frames (Zong et al., 2017), protected electronics, and connectorized systems with interchangeable cables (Barbera et al., 2016; Cai et al., 2016; Liberti et al., 2017; Jacob et al., 2018; De Groot et al., 2020). Optical components used in miniature endoscopes can be costly and, because of their size, failure can happen during surgical implantation or extraction. To counteract this, Bocarsly et al. (2015) proposed a version of the device, including the implantation in animal's brain of a guide cannula, allowing for the insertion of a GRIN lens for each imaging session. However, it should be noted that the resulting diameter of the imaging probe is larger, which has an impact on brain tissue, as previously reported (Bocarsly et al., 2015; Resendez et al., 2016).

\section{Two-Color Mini-Endoscopes}

Functional and structural imaging in a given brain region was, for a long time, restricted to a general cell population or a subset of cells expressing a particular $\mathrm{Ca}^{2+}$ indicator or fluorescent marker. More recently, two-color versions of mini-endoscopes have been developed that allow two different fluorophores with different emission and excitation wavelengths to be imaged. However, GRIN lenses have large chromatic aberrations that induce a shift (sometimes up to several tens of microns) in the imaged focal plane when comparing the fluorescence of two different fluorophores. To counteract these aberrations, one solution is to place two CMOS sensors in the microscope body at a specific location to compensate for the focal shift induced by the GRIN lens when imaging the two spectrally distinct fluorophores. Another solution for counteracting chromatic aberrations is to use achromatic lenses. The availability of several versions and colors of GECIs (Dana et al., 2016, 2019; Shen et al., 2020), each with its own emission/excitation spectra, means that it is now possible to image using both green and red $\mathrm{Ca}^{2+}$ indicators with similar kinetics (Shen et al., 2020). Twocolor mini-endoscopes have a number of advantages. First, when combined with $\mathrm{Ca}^{2+}$ indicators of spectrally distinguishable colors (GCaMP and RCaMP, for instance), it is possible to compare the activity of two different cell populations in the same brain region of freely behaving animals. In addition, two-color mini-endoscopes can be used for motion correction. In fact, $x y$ and $z$ drift can occur when animals are moving, which may create some bias in data analysis and interpretation. This issue can be addressed by performing functional $\mathrm{Ca}^{2+}$ imaging combined with morphological fluorescent marker imaging followed by open-source plugin or software processing for motion and drift correction. These systems can be also used for imaging cell populations that can be defined only based on the combinatory genetic labeling approaches, leading to the expression of two different fluorophores (or sensors) by the same cell. Two-color mini-endoscopes can be also used for assessing the interplay between different cellular populations in a given brain region. It should be noted, however, that because of their optical design, two-color mini-endoscopes are bulkier and a longer habituation period for the animal may be required before starting the experiments.

\section{Combined Optogenetic and Imaging Mini-Endoscopes for Studying Brain Connectivity and Disease Pathogenesis}

The discovery that neuronal activity can be modulated using light-sensitive ion channels or opsins was a breakthrough in the field of neuroscience (Kim et al., 2017). In vivo optogenetic approaches are now widely used to modulate 
neuronal activity and to investigate the impact on animal behavior (Kim et al., 2017). It is possible to modulate neuronal activity by either stimulating or inhibiting the activity of a cell population in a given structure while simultaneously imaging the responses of the same or neighboring populations of cells in the same structure or even in a very different, remote structure (Stamatakis et al., 2018). However, the opsin and $\mathrm{Ca}^{2+}$ indicators have to be carefully chosen as crosstalk between the channels may affect the recordings (Stamatakis et al., 2018). In addition, the imaging light source attenuates the optogenetic response (Stamatakis et al., 2018), which means that care must be taken in choosing the excitation light source for imaging in order to provide a better signal-to-noise ratio and minimal crosstalk.

De Groot et al. (2020) developed the NINscope, which can be used to simultaneously record and optogenetically stimulate two distant brain structures. The authors reduced the footprint of the mini-endoscope, making it possible to record the $\mathrm{Ca}^{2+}$ activity of a subset of cells in a given brain region while optogenetically stimulating cells in many other brain areas using small LEDs installed on the surface of the brain (De Groot et al., 2020). For experiments requiring optogenetic manipulation of deeper brain regions that cannot be targeted with the NINscope, a micro-LED can be implanted inside the brain. The stimulation can then be synchronized with the endoscope imaging (Shin et al., 2017). Combined optogenetic and imaging mini-endoscope baseplates composed of a GRIN relay lens for fluorescence imaging and an optical fiber for opsin activation are also commercially available. These systems offer a customizable length and distance between the imaging cannula and the implanted optical fiber. We used one of these mini-endoscope baseplates to optogenetically induce $\alpha$-synuclein aggregation in the substantia nigra and to monitor changes in striatal neurons using $\mathrm{Ca}^{2+}$ imaging (Bérard et al., 2019).

\section{Multi-Region Imaging With Mini-Endoscopes}

The NINscope developed by De Groot et al. (2020) also allows the simultaneous and synchronous imaging of two separate brain regions because of its reduced footprint. This is of particular relevance in a context of brain connectivity as the activity of two distinct regions can be correlated at the cellular level depending on the selected behaviors or stimuli. Simultaneous recording using two separate mini-endoscopes can also be performed in both hemispheres of the same structure (Gonzalez et al., 2019; De Groot et al., 2020). These recordings can be used to investigate the lateralization of brain activity (Gonzalez et al., 2019) and to compare, in the same subject, the activity of two hemispheres to which a different treatment may have been applied. A device allowing for simultaneous imaging of different brain regions is now also commercially available. In fact, because of it small footprint, the fiber bundlebased device from Neurescence (quartet mini-microscope) can record neuronal activity from up to four different brain regions as well as from different animals that are socially interacting, for instance.

\section{Mini-Endoscopes With Dual-Modality Recordings}

Mini-endoscopes also allow for dual-modality recording of neuronal activity. Yashiro et al. (2017) used a mini-endoscope system coupled with electrophysiological recordings of neural activity to make simultaneous optical recordings from large neuronal subsets. Such simultaneous optical and electrical recordings may prove to be extremely useful in correlating electrically recorded phenomena (multi-unit activity and local field potentials) with optically recorded $\mathrm{Ca}^{2+}$ fluctuations. Combined electrical and $\mathrm{Ca}^{2+}$ signal recordings from a single fluorescent neuron in vivo have also been made and allow the spiking activity of recorded cells to be correlated with changes in $\mathrm{Ca}^{2+}$ dynamics (Lechasseur et al., 2011). In addition to combining imaging and electrophysiological recordings, commercially available dual implant baseplates composed of a GRIN lens and an optical fiber allow $\mathrm{Ca}^{2+}$ imaging and photometry recordings in two different brain regions located as close together as $1 \mathrm{~mm}$ to be performed. Another potential new application for mini-endoscopes involves combining $\mathrm{Ca}^{2+}$ imaging with intrinsic optical signals (Senarathna et al., 2019). This device can be used to monitor neuronal activity in large areas of the brain and subtract the hemodynamic signal, providing insights into neurovascular coupling (Senarathna et al., 2019). Other types of dual-modality recording mini-endoscopes are also available, such as those that allow for combined $\mathrm{Ca}^{2+}$ imaging and bird vocalization recording (Liberti et al., 2017). It is likely that in coming years other dual-modality mini-endoscopes will be developed. These systems could allow for combining imaging and local drug delivery via integrated cannula, $\mathrm{Ca}^{2+}$ activity recordings and respiration/sniffing assessments, or simultaneous $\mathrm{Ca}^{2+}$ and voltage imaging, for instance. This in turn will make it possible to perform multi-modal assesments of neural networks during unrestricted animal behavior.

\section{Electronic Modulation of the Field of View: eFocus Mini-Endoscopes}

A non-negligible drawback of traditional mini-endoscopes was, for a long time, the inability to change the focus prior to or during image acquisition, limiting imaging to a single focal plane (Barretto and Schnitzer, 2012; Hamel et al., 2015). Indeed over time, following consecutive imaging sessions, the focal plane can change slightly and tracking the same cells can become challenging. To counteract this, the first versions of commercial and open-source mini-endoscopes offered the possibility to manually and mechanically adjust the image focus with a slider, screw, or turret before starting a recording, which resulted in additional manipulations of both the device and the animal (Ghosh et al., 2011; Barbera et al., 2016; Cai et al., 2016; Liberti et al., 2017; Jacob et al., 2018). To deal with this issue, updated electronically focused versions of endoscopes have been released by several companies such as Inscopix and Doric Lenses or were built from open-source designs (e.g., UCLA miniscope version 4). These versions make it possible to adjust the focus remotely and thus avoid mechanical manipulations of the endoscope while the animals are freely behaving. To that end, several groups 
have taken advantage of different strategies. For example, electrowetting liquid lenses, which are small devices containing two non-miscible liquids, have been used. They allow for the rapid deformation of the lenses and thus the electronic focusing of the field of view by applying a voltage (Grewe et al., 2011; Zou et al., 2015; Ozbay et al., 2018). Electronically tunable liquid crystal lenses have also been used (Bagramyan et al., 2017). These lenses, which are traditionally used in liquid crystal displays, consume little energy and are lighter than electro-wetting liquid lenses, two important parameters for improving mini-endoscopes without compromising their size and weight.

\section{IN VIVO APPLICATIONS OF MINI-ENDOSCOPIC IMAGING}

As discussed above, two main approaches for optical brain imaging studies on live animals have emerged - those that require the experimental subjects to be head-fixed, such as two-photon excitation microscopy, and those that allow for unrestrained behavior, such as mini-endoscopes. Each technique has its share of advantages and drawbacks. Depending on the nature of the study, researchers can now use a variety of methods that can accommodate either imaging approach. New advancements in fluorescent reporter proteins, in particular GECIs and GEVIs, mean that neuroscientists can perform two-color fluorescence imaging and can distinguish the activity of a dual-labeled subset within a broad population of indicator-labeled cells (Chen et al., 2013; Inoue et al., 2015; Malvaut et al., 2017). The head-fixed imaging approaches that use high-performance lenses and the optical sectioning provided by two-photon microscopy allow for the interrogation of activity patterns during animal behavior at subcellular levels such as in dendrites, dendritic spines, and even axonal boutons (Petreanu et al., 2012; Xu et al., 2012; Boyd et al., 2015; Sheffield and Dombeck, 2015). The headfixed paradigm can also make intracranial drug delivery easier (Nimmerjahn et al., 2009; Lovett-Barron et al., 2014). Behavioral assays, including adapted fear conditioning paradigms (LovettBarron et al., 2014), controlled delivery of sensory stimuli (Verhagen et al., 2007; Carey et al., 2009; Andermann et al., 2011; Blauvelt et al., 2013; Patterson et al., 2013; Miller et al., 2014), and perceptual discrimination tasks (Andermann et al., 2010; Komiyama et al., 2010; O'connor et al., 2010) can now be done in a head-restrained configuration to study changes at subcellular levels during complex behavioral tasks. Another exciting avenue for head-restrained optical imaging in live animals involves the use of virtual reality approaches (Harvey et al., 2009, 2012; Dombeck et al., 2010), which could provide new information about an animal's spatial navigation.

However, even with the enrichment of the behavioral repertoire that can be tested during head-restrained experiments, the array of behavioral manipulations is still restricted and is associated with the stress that the animals may encounter during head fixation and imaging. This stress can have an adverse effect on the outcome of the behavioral analysis and is likely to affect the neuronal activity patterns recorded (Thurley and Ayaz, 2017). Miniaturized head-mounted imaging devices were designed to circumvent these shortcomings. The main motivation for these devices was first and foremost their ability to record activity from many neurons in an animal that is unrestrained and that can display natural innate behavior as well as a broad array of social behaviors such as fighting, mating, care-giving, and other forms of interaction. The need to accurately monitor cell activity in freely behaving experimental subjects has led to recent advances in mini-endoscopic imaging that make it possible to record neuronal activity simultaneously from different brain regions (De Groot et al., 2020), to combine $\mathrm{Ca}^{2+}$ imaging and recordings of other modalities such as electrical recordings of neural activity (Yashiro et al., 2017) or sound vocalizations (Liberti et al., 2017), and to image activity in neural networks at different focal planes and in different neuronal populations using efocus and twocolor versions of mini-endoscopes. Also, the versatility of miniendoscopes enables cell activity to be tracked across a large array of behavioral paradigms established over the last decades (Morris, 1984; Graeff et al., 1998; Nadler et al., 2004).

The main in vivo application for mini-endoscopes is the imaging of GECIs in large subsets of neurons in freely behaving animals. As mini-endoscopes have many useful characteristics such as relative ease of use, scalability, and commercial availability, they have seen a significant spread to numerous research fields. The use of mini-endoscopes in neurosciencerelated fields such as learning and memory, neuropsychiatric disorders, and drug discovery has enabled scientists to accurately describe temporal changes that neuronal circuits exhibit during memory formation and retention as well as modifications due to a pathology. The field of learning and memory has in particular been directly influenced by the development of mini-endoscopes. Tracking the formation and subsequent modification of cellular ensembles that retain learned information, or engrams, over long periods of time has allowed neuroscientists to answer questions about the coding dynamics underlying the neurobiology of longterm memory (Tian et al., 2009; Cai et al., 2016). Established behavioral assays coupled with long-term monitoring of cellular activity has revealed that activity-induced modifications in neuronal CREB (cAMP response element-binding protein) levels are encoded by a shared neural ensemble in the CA1 part of the hippocampus that links distinct contextual memories occurring close in time (Cai et al., 2016). Neuronal activity in the spinal cord of freely behaving mice has also been recorded using a vertebraaffixed mini-endoscope (Sekiguchi et al., 2016). Implanting a mini-endoscope in the spinal cord is technically more challenging than anchoring an implant on top of the skull due to the pronounced movement of the spine within the vertebral column. Although fewer cells can be imaged due the curvature of the spinal cord, these experiments showed that distinct cutaneous stimuli activate overlapping ensembles of dorsal horn neurons and that stimulus type and intensity are encoded at the single-cell level (Sekiguchi et al., 2016).

Mini-endoscopic applications are not limited to the field of learning and memory. Mouse models of diseases are very important for studying the neurobiological basis of a myriad of brain disorders. As most of these diseases are, to some extent, characterized by a deficit in information processing, imaging neural activity in transgenic and knockout mice could 
be very advantageous for elucidating the underpinnings of the disease mechanisms (Nestler and Hyman, 2010). For example, much more information about alterations in coding dynamics in animal disease models can be inferred from large-scale imaging in freely behaving animals than is possible with electrophysiological measurements. These approaches could also narrow the gap between molecular and behavioral analyses. This concept becomes clear in the context of Alzheimer's disease $(\mathrm{AD})$, where much progress in understanding the molecular pathology underlying the neurodegeneration observed in human patients has led to the emergence of different mouse models that exhibit one or more AD hallmarks (b-amyloid, presenilins, apolipoprotein E, and Tau) (Knowles et al., 2009; Sterniczuk et al., 2010; Filali et al., 2012; Youmans et al., 2012). However, little is known about how these molecular pathways influence population dynamics during memory encoding and retrieval. With the advent of mini-endoscopy, longitudinal imaging in different $\mathrm{AD}$ models during the performance of memory tests is now feasible and could shed new light on memory coding dysfunctions in $\mathrm{AD}$ as well as in other neurological and psychiatric disorders (Ziv and Ghosh, 2015). As in the case of $\mathrm{AD}$, the use of mini-endoscopes in animal models of other neurodegenerative disorders and brain trauma may allow the early hallmarks of disease manifestation to be deciphered. These mini-endoscopes combined with optogenetic stimulation can also be used to induce molecular alterations in cells and study disease progression. For example, it is now possible to optogenetically induce the aggregation of $\alpha$-synuclein in dopaminergic neurons in the substantia nigra and to study alterations in the nigrostriatal pathway and in the network activity of striatal neurons using longitudinal mini-endoscopic $\mathrm{Ca}^{2+}$ imaging (Bérard et al., 2019).

Drug discovery could also benefit from mini-endoscopic imaging. Although much research has focused on the pharmacological and molecular mechanisms of drugs at the cellular level, much less attention has been directed at understanding the effect of drugs on neuronal coding. Berdyyeva et al. (2014) showed that a GABA-A agonist used for treating insomnia reduces hippocampal neuronal firing in freely behaving mice. This result, although not surprising, shed light on the need to correlate neuronal dynamics with the effects of chronic drug administration and to identify the effects of the drugs on the overall neuronal network. Addressing these issues would further advance our ability to design future therapies for treating brain diseases (Ziv and Ghosh, 2015).

The capability of mini-endoscopes to record neural activity in freely behaving animals can be further enhanced by using optogenetic stimulations (Stamatakis et al., 2018) or by combining two different recording techniques such as extracellular electrophysiological recordings with $\mathrm{Ca}^{2+}$ imaging in freely behaving animals (Yashiro et al., 2017). Stamatakis et al. (2018) used a mini-endoscope that jointly records optical neural activity and light-induced alterations of cellular ensemble activity in the same field-of-view. Other researchers have used a device to optogenetically stimulate brain regions away from the imaging field-of-view (Shin et al., 2017; Bérard et al., 2019; Senarathna et al., 2019). Engineering advances in the manufacture of mini-endoscopes have led to a reduction in the weight and size of these devices, making it possible to simultaneously record cellular activities in different brain regions as was done using the NINscope (De Groot et al., 2020). Such types of experiments will yield new data subsets that can be used to analyze the extent to which lateralization occurs during behavior and learning and to track the network stability of multi-region cellular ensembles over long periods of time (Gonzalez et al., 2019).

Mini-endoscopes are mostly used to investigate in vivo brain function in freely behaving animals by $\mathrm{Ca}^{2+}$ imaging of cell populations in a given region and are evolving in parallel with improvements in GECIs. The use of such powerful tools will likely expand to the study of other processes underlying brain activity. For instance, an in vivo two-photon investigation of adult neurogenesis and, more particularly, stem cell division has been already performed in anesthetized head-restrained animals (Pilz et al., 2018). Mini-endoscopes could help unravel this process in freely behaving animals and to correlate stem cell division with naturalistic patterns of animal behavior. These experiments can be performed under homeostatic conditions in known neurogenic regions of the brain like the dentate gyrus or the subventricular zone, as well as after injury and neuronal regeneration. In line with this, mini-endoscopic imaging has shown that coupling preexisting neurons to the cerebrovascular system regulates adult hippocampal neurogenesis (Shen et al., 2019) and that newborn neurons in the adult dentate gyrus migrate laterally first to increase their dispersion (Wang et al., 2019). The migration of neuronal progenitors and microglial cells following different neurodegenerative disorders and brain trauma can also be recorded by mini-endoscopic imaging. In addition, the use of miniaturized two-photon microscopes makes it possible to image $\mathrm{Ca}^{2+}$ activity in dendrites (Zong et al., 2017) and may be used in the future to image other sub-cellular structures. Future studies will certainly deepen our understanding of the cellular and molecular mechanisms operating in homeostatic and diseased conditions.

\section{LIMITATIONS AND FUTURE AVENUES FOR MINI-ENDOSCOPIC IMAGING}

Given the experimentally proven benefits and versatility of miniendoscopes for neuroscience research, it has become increasingly clear that the impact of these devices will grow exponentially. However, they still have some limitations and drawbacks and further improvements are needed. The weight and size of miniendoscopes are crucial and should be further improved to enable unrestrained one- and two-photon mini-endoscopic imaging in freely behaving mice and other small animal models. Similarly, the footprint of mini-endoscopes should be reduced for multiregion imaging in order to record activity from adjacent brain areas. Another caveat is that most of the mini-endoscopes used in freely behaving animals need to be tethered to optical components that are too big and too heavy to be mounted on an animal's head, which means that more complex social behaviors 
such as social interactions, mating, and mate aggression cannot be fully investigated due to the obvious physical constraints. The poor optical sectioning of one-photon mini-endoscopes and the major aberrations caused by their optical components (GRIN lenses) should also be taken into consideration and be improved. Below we discuss some of the avenues for addressing these issues.

\section{Optical Sectioning}

Despite the advantages of wide-field epifluorescence miniendoscopy (large field of view, small dimensions, and technical simplicity), these systems do not provide the optical sectioning of widely used tabletop systems such as confocal or two-photon microscopes or two-photon mini-endoscopes. As a consequence, image contrast in the focal plane is strongly attenuated by the outof-focus fluorescent background when imaging densely labeled structures, especially in scattering media. The strong background limits neuronal and glial activity recording to the soma, as smaller structures such as dendrites, dendritic spines, and glial processes are too dim to be resolved. One of the key avenues for future developments is thus the integration and miniaturization of non-scanning optical sectioning systems already offered in large-scale microscopes.

Among non-scanning techniques, the tabletop version of the HiLo microscope has generated a great deal of interest (Lim et al., 2011; Lauterbach et al., 2015). The HiLo microscopy technique is based on epifluorescence microscopy and makes it possible to reject the out-of-focus fluorescent background by processing two images, one recorded with a uniform illumination and the other recorded with a high contrast pattern. HiLo microscopy provides high contrast images with optical sectioning similar to confocal microscopy at the expense of half the camera frame rate. The use of speckle illumination for the high contrast illumination has been proposed, as fast switching from uniform to speckle illumination can be obtained with the simple addition of a diffuser and a galvanometric scanner. HiLo microscopy has already been used for endoscopic applications using a flexible fiber bundle to deliver shaped illumination to the sample and to collect the fluorescence (Ford et al., 2012). Although fiber bundles allow images and illumination patterns to be relayed over long distances (up to meters), they are more rigid than the smaller diameter multi-mode fibers used to deliver light in experiments on freely behaving animals. They also have a small core fill factor, which results in low optical transmission. These properties limit their use for dimmer fluorescent signal recording in freely behaving small animals. Generating both illumination types in the microscope body at the expense of the size of the system is a good alternative to fiber bundles, and the technical simplicity of the HiLo microscopy technique makes it a good candidate for miniaturization.

More recently, it has been proposed that the light field microscopy (LFM) and seeded iterative demixing (SID) techniques can be integrated into miniaturized microscopes (Nobauer et al., 2017; Skocek et al., 2018). These computational methods only require minor hardware modifications to the microscope body by inserting a microlens array in the detection pathway of a miniaturized epifluorescence microscope. A $700 \mu \mathrm{m} \times 600 \mu \mathrm{m} \times 360 \mu \mathrm{m}$ volume has been imaged at a frequency of $16 \mathrm{~Hz}$ with a discrimination threshold between cells of 15 microns. Despite the complex analytics and lower spatial resolution of this method, the reduced number of optical components and the extraction of a large volumetric amount of data makes it a good candidate for $\mathrm{Ca}^{2+}$ activity recording in freely behaving animals with improved optical sectioning.

As mentioned above, the first versions of mini-endoscopes were based on a two-photon excitation principle that provides superior optical sectioning (Helmchen et al., 2001; Helmchen, 2002; Flusberg et al., 2005). However, these systems are bulkier and heavier, which limits the behavioral paradigms that can be studied. In these versions, the laser scanning mechanism is either located proximally on the animal for higher resolution and sensitivity, or remotely and is connected to the animal with a fiber bundle to limit the number of optical components on the animal (Ozbay et al., 2015, 2018). To reduce the weight of the imaging systems, miniaturized scanning systems were developed based on micro-mechanical systems (MEMS), scanning mirrors (Piyawattanametha et al., 2006; Zong et al., 2017), and piezoelectric actuators (Engelbrecht et al., 2008). High resolution miniaturized two-photon mini-endoscopes capable of imaging a $130 \mu \mathrm{m} \times 130 \mu \mathrm{m}$-field of view at $40 \mathrm{~Hz}$ have been used to record $\mathrm{Ca}^{2+}$ activity in dendrites and spines in freely behaving animals (Zong et al., 2017). In this system, a hollow core photonic crystal fiber and an achromatic objective lens are used to minimize light pulse broadening and maintain the high intensity at focus essential for two-photon excitation. However, this work was done in the first layers of the brain (visual cortex). Minimizing pulse broadening remains one of the main challenges of deep brain imaging. To achieve this, the chromatic aberration of the GRIN lenses used for deep brain imaging has to be properly compensated without increasing the outer diameter of the implant. This will require the development of new minimally invasive achromatic optical probes. Another interesting approach to increase the imaging depth without using GRIN lenses is miniaturized three-photon microscopy. Klioutchnikov et al. (2020) recently designed a three-photon microscope capable of recording calcium transients at multiple cortical depths of up to 1120 microns in freely behaving animals. However, the weight of the device developed by Klioutchnikov et al. (2020) (around $5 \mathrm{~g}$ ) restricts its use for now to bigger rodents such as rats.

Miniaturized confocal microscopes with a scanning system placed on the animal would provide optical sectioning without a complex laser system and non-linear effect management. The main drawback of confocal microscopy compared to two-photon microscopy is its lower excitation wavelength, which creates more scattering and higher phototoxicity. The chromatic aberrations of the optical system, including the GRIN relay lens, will also have to be properly compensated to ensure that the pinhole and object plane remain in conjugated planes.

\section{Optical Aberration Compensation}

The high numerical aperture and the small outer diameter of GRIN lenses $(0.5-1 \mathrm{~mm})$ allow the imaging of structures located several millimeters deep in tissue with minimal invasiveness. In comparison, relay lenses made of optically homogenous materials 
with a similar numerical aperture are at least five times larger in diameter. Given this, GRIN lenses have become the preferred option for in vivo deep structure imaging. However, GRIN lenses also suffer from high intrinsic on-axis and off-axis optical aberrations (astigmatism and chromatic) and have the highest optical aberrations in miniaturized microscopy systems, leading to lower spatial resolutions and smaller effective fields of view, especially with high numerical aperture GRIN lenses. To solve this issue, adaptive optics methods have been used in two-photon mini-endoscopes. One of these methods allows the recovery of diffraction-limited resolution in a large field of view by measuring and correcting off-axis aberrations using pupil segmentationbased adaptive optics (Wang and Ji, 2012). Future developments in miniature microscopy would also benefit from the use of miniature tunable liquid crystal lenses and miniaturization of the phase modulators used in adaptive optics methods such as phase liquid crystal spatial light modulators. Adding adaptive optics to miniaturized microscopes would also help reduce the impact of light scattering in tissue. The inhomogeneity created by the different components of the sample (water, proteins, and lipids, etc.) distorts the fluorescence wavefront, resulting in lower resolution and contrast.

\section{Wireless Imaging Systems}

With the development of tethered miniaturized microscopes, it became possible to correlate brain activity and behavior recordings. However, despite several attempts to reduce the impact of the cables on animal behavior (very flexible cables, motor-assisted rotary-joints, etc.), some complex behavioral studies such as social interaction studies with multiple animals cannot be performed with these systems due to cable entanglement. To overcome these issues, several wireless models have been proposed (Liberti et al., 2017; Barbera et al., 2019; Shuman et al., 2020). One of the main challenges in developing wireless systems is minimizing their size and weight by, for instance, reducing the size of the lithium polymer (LiPo) batteries. Several avenues have been explored to reduce power consumption and use lighter batteries: limiting the number of on-board electronic components with on-site recording (Barbera et al., 2019; Shuman et al., 2020) and using low resolution sensors to restrict the amount of transferred data (Liberti et al., 2017). Using a battery backpack for a better distribution of the weight has also been explored (Barbera et al., 2019). For example, Liberti et al. (2017) introduced the FinchScope, a wireless mini-endoscope that uses a $2 \mathrm{~g}$ wireless transmitter and a LiPo battery. Barbera et al. (2019) also introduced a wireless mini-endoscope that is powered by a battery backpack anchored on the animal's back and that is equipped with Micro SD card storage. They were able to record the activity of medium spiny neurons (MSNs) in the dorsal striatum of two freely behaving and interacting mice. In both studies, power was supplied to the microscope by miniature LiPo batteries, which depending on their size, can provide power for $30 \mathrm{~min}$ to $1 \mathrm{~h}$ at the expense of increasing the weight of the microscope to several grams (Liberti et al., 2017). For future developments, local recording remains a very good solution for reducing the weight of the system.
Transferring data samples at a very low frame rate $(0.2-1 \mathrm{~Hz})$ and adding a communication interface for the synchronization with external components such as behavior cameras would improve system feedback. The development of new wireless systems should also take into account future behavioral studies aiming to assess the impact of the weight and its distribution (e.g., backpack battery versus integrated battery) on animal behavior. Further improvements are required to optimize wireless mini-endoscopes, improvements that will largely benefit the neuroscience field by expanding the number of possible behavioral experiments that can be performed while monitoring brain activity. The potential of this technique can also be extended to animals that exhibit more complex social behavior like monkeys and small primates. In addition, more complex social behaviors can be assessed without the constraints of the cable from the imaging device.

\section{GENERAL CONCLUSION}

Imaging neuronal activity using various sensors and actuators has emerged as a powerful tool that allows neuroscientists to record large-scale neuronal activity in freely behaving animals. Traditional tools used for imaging such as two-photon excitation microscopy have opened up the possibility of imaging $\mathrm{Ca}^{2+}$ activity patterns at the cellular and subcellular levels with unprecedented optical resolution. But these experimental setups are costly and require specific infrastructures that limit their dissemination among large numbers of laboratories. Also, these setups require the animals to be head-restrained during the imaging phase, which markedly limits the behavioral repertoire that can be tested. The development of mini-endoscopes has given rise to a new class of devices that have proven to be very useful in acquiring and correlating functional cellular signals from cortical and deep brain regions to animal behavior. The ease of use coupled with the portability and relative low cost of miniendoscopes has provided a much-needed technical alternative. The capacity to take recordings from large neuronal populations in freely behaving animals has made it possible to analyze large-scale $\mathrm{Ca}^{2+}$ imaging data with higher statistical power and to discover different types of coding dynamics related to animal behavior. The versatility of these devices also provides a good platform for improvements to the original design based on research requirements. Designs that incorporate parallel electrophysiological recordings or that allow all-optical circuitlevel investigations by combining imaging with optogenetic manipulations can be used to further dissect activity at the microcircuit level and increase our understanding of neural processes underlying animal behavior. The ability to construct lightweight small mini-endoscopes will contribute to animal wellbeing, will improve the read-out of neural activity under natural conditions, and will expand research to other animal models. By decreasing the size of these devices, mini-endoscopes now also permit the use of multiple devices on the same experimental subject, which allows for the imaging of multiple brain areas in mice and other larger animals such as rats and primates. This multi-site recording approach will open up new avenues 
for systems neuroscience research, where longitudinal largescale recordings beyond a single local circuit can be performed and may uncover exciting new information related to circuit activity patterns governing brain-wide functional circuitry and synchronicity. Further improvements to these devices aiming to increase the depth of penetration in living tissue, fine tune spatial and temporal resolution, and add a wireless option for even less restrictive behavioral repertoires are needed to make functional imaging in freely behaving animals more widely accessible. The traditional use of mini-endoscopy is to image $\mathrm{Ca}^{2+}$ activity at the neuronal level. However, the advances in fluorescent reporters, onsite lens focus technologies, and two- and three-photon miniaturization will enable scientists to image cellular and subcellular compartments such as dendrites and dendritic spines. Further development of GEVIs, which have much more temporal resolution than GECIs, will push the use of mini-endoscopes even further, giving scientists the means to optically assess voltage changes across membranes and dendritic compartments. This will most likely revolutionize neuroscience research, giving scientists a tool to record, stimulate, and differentiate between the fast electrophysiological events associated with synaptic activity and the slow $\mathrm{Ca}^{2+}$ events associated with the various biomolecular processes that occur during learning

\section{REFERENCES}

Ahrens, M. B., Li, J. M., Orger, M. B., Robson, D. N., Schier, A. F., Engert, F., et al. (2012). Brain-wide neuronal dynamics during motor adaptation in zebrafish. Nature 485, 471-477. doi: 10.1038/nature11057

Andermann, M. L., Kerlin, A. M., and Reid, R. C. (2010). Chronic cellular imaging of mouse visual cortex during operant behavior and passive viewing. Front. Cell Neurosci. 4:3. doi: 10.3389/fncel.2010.00003

Andermann, M. L., Kerlin, A. M., Roumis, D. K., Glickfeld, L. L., and Reid, R. C. (2011). Functional specialization of mouse higher visual cortical areas. Neuron 72, 1025-1039. doi: 10.1016/j.neuron.2011.11.013

Bagramyan, A., Galstian, T., and Saghatelyan, A. (2017). Motion-free endoscopic system for brain imaging at variable focal depth using liquid crystal lenses. $J$ Biophoton. 10, 762-774. doi: 10.1002/jbio.201500261

Bando, Y., Sakamoto, M., Kim, S., Ayzenshtat, I., and Yuste, R. (2019). Comparative evaluation of genetically encoded voltage indicators. Cell Rep 26, e804.

Barbera, G., Liang, B., Zhang, L., Gerfen, C. R., Culurciello, E., Chen, R., et al. (2016). Spatially compact neural clusters in the dorsal striatum encode locomotion relevant information. Neuron 92, 202-213. doi: 10.1016/j.neuron. 2016.08.037

Barbera, G., Liang, B., Zhang, L., Li, Y., and Lin, D. T. (2019). A wireless miniScope for deep brain imaging in freely moving mice. J. Neurosci. Methods 323, 56-60. doi: 10.1016/j.jneumeth.2019.05.008

Barretto, R. P., and Schnitzer, M. J. (2012). In vivo optical microendoscopy for imaging cells lying deep within live tissue. Cold Spring. Harb. Protoc. 2012, 1029-1034.

Bérard, M., Sheta, R., Malvaut, S., Turmel, R., Alpaugh, M. J., Dubois, M., et al. (2019). Optogenetic-Mediated Spatiotemporal Control of $\alpha$ Synuclein Aggregation Disrupts Nigrostriatal Transmission and Precipitates Neurodegeneration. NEURON-D-19-01059. Available online at: https://ssrn. com/abstract=3416893 (accessed July 9, 2019).

Berdyyeva, T., Otte, S., Aluisio, L., Ziv, Y., Burns, L. D., and Dugovic, C. (2014). Zolpidem reduces hippocampal neuronal activity in freely behaving mice: a large scale calcium imaging study with miniaturized fluorescence microscope. PLoS ONE 9:e112068. doi: 10.1371/journal.pone.0112068

Berridge, M. J., Lipp, P., and Bootman, M. D. (2000). The versatility and universality of calcium signalling. Nat. Rev. Mol. Cell Biol. 1, 11-21. doi: 10. $1038 / 35036035$ and memory. In addition, mini-endoscopic imaging approaches may allow scientists to monitor activity related to spine formation/elimination, the dynamics of glia processes, microglia migration, and adult neurogenesis in freely behaving animals. The flexible methodological approach provided by miniendoscopes will continue to afford neuroscientists with better tools to image large neuronal populations during increasingly less restrained behavioral paradigms. This, in turn, will lead to new datasets that will more accurately depict the relationship between recorded functional and structural activities and animal behavior.

\section{AUTHOR CONTRIBUTIONS}

All authors listed have made a substantial, direct and intellectual contribution to the work, and approved it for publication.

\section{FUNDING}

This work was supported by a postdoctoral fellowship from Mitacs to SM and an operating grant from the Natural Sciences and Engineering Research Council of Canada (NSERC) to AS.

Berry, K. P., and Nedivi, E. (2017). Spine dynamics: are they all the same? Neuron 96, 43-55. doi: 10.1016/j.neuron.2017.08.008

Blauvelt, D. G., Sato, T. F., Wienisch, M., Knopfel, T., and Murthy, V. N. (2013). Distinct spatiotemporal activity in principal neurons of the mouse olfactory bulb in anesthetized and awake states. Front. Neural Circuits 7:46. doi: 10.3389/ fncir.2013.00046

Bocarsly, M. E., Jiang, W. C., Wang, C., Dudman, J. T., Ji, N., and Aponte, Y. (2015). Minimally invasive microendoscopy system for in vivo functional imaging of deep nuclei in the mouse brain. Biomed. Opt. Express 6, 4546-4556.

Boyd, A. M., Kato, H. K., Komiyama, T., and Isaacson, J. S. (2015). Broadcasting of cortical activity to the olfactory bulb. Cell Rep. 10, 1032-1039. doi: 10.1016/j. celrep.2015.01.047

Buzsaki, G. (2004). Large-scale recording of neuronal ensembles. Nat. Neurosci. 7, 446-451. doi: 10.1038/nn1233

Cai, D. J., Aharoni, D., Shuman, T., Shobe, J., Biane, J., Song, W., et al. (2016). A shared neural ensemble links distinct contextual memories encoded close in time. Nature 534, 115-118. doi: 10.1038/nature17955

Carey, R. M., Verhagen, J. V., Wesson, D. W., Pirez, N., and Wachowiak, M. (2009). Temporal structure of receptor neuron input to the olfactory bulb imaged in behaving rats. J. Neurophysiol. 101, 1073-1088. doi: 10.1152/jn.90902.2008

Chen, T. W., Wardill, T. J., Sun, Y., Pulver, S. R., Renninger, S. L., and Baohan, A. (2013). Ultrasensitive fluorescent proteins for imaging neuronal activity. Nature 499, 295-300. doi: 10.1038/nature 12354

Clapham, D. E. (1995). Calcium signaling. Cell 80, 259-268.

Csicsvari, J., Henze, D. A., Jamieson, B., Harris, K. D., Sirota, A., Bartho, P., et al. (2003). Massively parallel recording of unit and local field potentials with silicon-based electrodes. J. Neurophysiol. 90, 1314-1323. doi: 10.1152/jn.00116. 2003

Dana, H., Mohar, B., Sun, Y., Narayan, S., Gordus, A., Hasseman, J. P., et al. (2016). Sensitive red protein calcium indicators for imaging neural activity. Elife 5:e12727.

Dana, H., Sun, Y., Mohar, B., Hulse, B. K., Kerlin, A. M., Hasseman, J. P., et al. (2019). High-performance calcium sensors for imaging activity in neuronal populations and microcompartments. Nat. Methods 16, 649-657. doi: 10.1038/ s41592-019-0435-6

De Groot, A., Van Den Boom, B. J., Van Genderen, R. M., Coppens, J., Van Veldhuijzen, J., Bos, J., et al. (2020). NINscope, a versatile miniscope for multi-region circuit investigations. Elife 9:e49987. 
Dombeck, D. A., Harvey, C. D., Tian, L., Looger, L. L., and Tank, D. W. (2010). Functional imaging of hippocampal place cells at cellular resolution during virtual navigation. Nat. Neurosci. 13, 1433-1440. doi: 10.1038/nn.2648

Dombeck, D. A., Khabbaz, A. N., Collman, F., Adelman, T. L., and Tank, D. W. (2007). Imaging large-scale neural activity with cellular resolution in awake, mobile mice. Neuron 56, 43-57. doi: 10.1016/j.neuron.2007.08.003

Dupret, D., O'neill, J., Pleydell-Bouverie, B., and Csicsvari, J. (2010). The reorganization and reactivation of hippocampal maps predict spatial memory performance. Nat. Neurosci. 13, 995-1002. doi: 10.1038/nn.2599

Edell, D. J., Toi, V. V., Mcneil, V. M., and Clark, L. D. (1992). Factors influencing the biocompatibility of insertable silicon microshafts in cerebral cortex. IEEE Trans. Biomed. Eng. 39, 635-643. doi: 10.1109/10.141202

Engelbrecht, C. J., Johnston, R. S., Seibel, E. J., and Helmchen, F. (2008). Ultra-compact fiber-optic two-photon microscope for functional fluorescence imaging in vivo. Opt Express 16, 5556-5564.

Filali, M., Lalonde, R., Theriault, P., Julien, C., Calon, F., and Planel, E. (2012). Cognitive and non-cognitive behaviors in the triple transgenic mouse model of Alzheimer's disease expressing mutated APP, PS1, and Mapt (3xTg-AD). Behav. Brain Res. 234, 334-342. doi: 10.1016/j.bbr.2012.07.004

Flusberg, B. A., Jung, J. C., Cocker, E. D., Anderson, E. P., and Schnitzer, M. J. (2005). In vivo brain imaging using a portable 3.9 gram two-photon fluorescence microendoscope. Opt. Lett. 30, 2272-2274.

Flusberg, B. A., Nimmerjahn, A., Cocker, E. D., Mukamel, E. A., Barretto, R. P., Ko, T. H., et al. (2008). High-speed, miniaturized fluorescence microscopy in freely moving mice. Nat. Methods 5, 935-938. doi: 10.1038/nmeth.1256

Ford, T. N., Lim, D., and Mertz, J. (2012). Fast optically sectioned fluorescence HiLo endomicroscopy. J. Biomed. Opt. 17, 021105. doi: 10.1117/1.jbo.17.2. 021105

Fu, O., Iwai, Y., Kondoh, K., Misaka, T., Minokoshi, Y., and Nakajima, K. I. (2019). SatB2-expressing neurons in the parabrachial nucleus encode sweet taste. Cell Rep. 27, 1650-1656.e1654.

Gengatharan, A., Bammann, R. R., and Saghatelyan, A. (2016). The role of astrocytes in the generation, migration, and integration of new neurons in the adult olfactory bulb. Front. Neurosci. 10:149. doi: 10.3389/fnins.2016.00149

Ghosh, K. K., Burns, L. D., Cocker, E. D., Nimmerjahn, A., Ziv, Y., Gamal, A. E., et al. (2011). Miniaturized integration of a fluorescence microscope. Nat. Methods 8, 871-878. doi: 10.1038/nmeth.1694

Gobel, W., Kerr, J. N., Nimmerjahn, A., and Helmchen, F. (2004). Miniaturized two-photon microscope based on a flexible coherent fiber bundle and a gradient-index lens objective. Opt. Lett. 29, 2521-2523.

Gonzalez, W. G., Zhang, H., Harutyunyan, A., and Lois, C. (2019). Persistence of neuronal representations through time and damage in the hippocampus. Science 365, 821-825. doi: 10.1126/science.aav9199

Graeff, F. G., Netto, C. F., and Zangrossi, H. Jr. (1998). The elevated T-maze as an experimental model of anxiety. Neurosci. Biobehav. Rev. 23, 237-246. doi: 10.1016/s0149-7634(98)00024-4

Grewe, B. F., and Helmchen, F. (2009). Optical probing of neuronal ensemble activity. Curr. Opin. Neurobiol. 19, 520-529. doi: 10.1016/j.conb.2009.09.003

Grewe, B. F., Voigt, F. F., van 't Hoff, M., and Helmchen, F. (2011). Fast two-layer two-photon imaging of neuronal cell populations using an electrically tunable lens. Biomed. Opt. Express 2, 2035-2046.

Grinvald, A., Frostig, R. D., Lieke, E., and Hildesheim, R. (1988). Optical imaging of neuronal activity. Physiol. Rev. 68, 1285-1366.

Gulati, S., Cao, V. Y., and Otte, S. (2017). Multi-layer cortical Ca2+ imaging in freely moving mice with prism probes and miniaturized fluorescence microscopy. J. Vis. Exp. 55579.

Hafting, T., Fyhn, M., Molden, S., Moser, M. B., and Moser, E. I. (2005). Microstructure of a spatial map in the entorhinal cortex. Nature 436, 801-806. doi: 10.1038/nature03721

Hamel, E. J., Grewe, B. F., Parker, J. G., and Schnitzer, M. J. (2015). Cellular level brain imaging in behaving mammals: an engineering approach. Neuron 86, 140-159. doi: 10.1016/j.neuron.2015.03.055

Harris, K. D., Csicsvari, J., Hirase, H., Dragoi, G., and Buzsaki, G. (2003). Organization of cell assemblies in the hippocampus. Nature 424, 552-556. doi: 10.1038/nature01834

Harvey, C. D., Coen, P., and Tank, D. W. (2012). Choice-specific sequences in parietal cortex during a virtual-navigation decision task. Nature 484, 62-68. doi: $10.1038 /$ nature10918
Harvey, C. D., Collman, F., Dombeck, D. A., and Tank, D. W. (2009). Intracellular dynamics of hippocampal place cells during virtual navigation. Nature 461, 941-946. doi: 10.1038/nature08499

Helmchen, F. (2002). Miniaturization of fluorescence microscopes using fibre optics. Exp. Physiol. 87, 737-745. doi: 10.1113/eph8702478

Helmchen, F., Fee, M. S., Tank, D. W., and Denk, W. (2001). A miniature headmounted two-photon microscope. High-resolution brain imaging in freely moving animals. Neuron 31, 903-912. doi: 10.1016/s0896-6273(01)00421-4

Houweling, A. R., and Brecht, M. (2008). Behavioural report of single neuron stimulation in somatosensory cortex. Nature 451, 65-68. doi: 10.1038/ nature 06447

Inoue, M., Takeuchi, A., Horigane, S., Ohkura, M., Gengyo-Ando, K., and Fujii, H. (2015). Rational design of a high-affinity, fast, red calcium indicator R-CaMP2. Nat. Methods 12, 64-70. doi: 10.1038/nmeth.3185

Inoue, M., Takeuchi, A., Manita, S., Horigane, S. I., Sakamoto, M., and Kawakami, R. (2019). Rational engineering of XCaMPs, a multicolor GECI suite for in vivo imaging of complex brain Circuit dynamics. Cell 177, 1346-1360.e1324.

Jacob, A. D., Ramsaran, A. I., Mocle, A. J., Tran, L. M., Yan, C., Frankland, P. W., et al. (2018). A compact head-mounted endoscope for in vivo calcium imaging in freely behaving mice. Curr. Protoc. Neurosci. 84:e51. doi: 10.1002/cpns.51

Jercog, P., Rogerson, T., and Schnitzer, M. J. (2016). Large-scale fluorescence calcium-imaging methods for studies of long-term memory in behaving mammals. Cold Spring Harb. Perspect. Biol. 8, a021824. doi: 10.1101/ cshperspect.a021824

Jung, J. C., and Schnitzer, M. J. (2003). Multiphoton endoscopy. Opt. Lett. 28, 902-904.

Kerr, J. N., De Kock, C. P., Greenberg, D. S., Bruno, R. M., Sakmann, B., and Helmchen, F. (2007). Spatial organization of neuronal population responses in layer $2 / 3$ of rat barrel cortex. J. Neurosci. 27, 13316-13328. doi: 10.1523/ jneurosci.2210-07.2007

Kim, C. K., Adhikari, A., and Deisseroth, K. (2017). Integration of optogenetics with complementary methodologies in systems neuroscience. Nat. Rev. Neurosci. 18, 222-235. doi: 10.1038/nrn.2017.15

Klioutchnikov, A., Wallace, D. J., Frosz, M. H., Zeltner, R., Sawinski, J., Pawlak, V., et al. (2020). Three-photon head-mounted microscope for imaging deep cortical layers in freely moving rats. Nat. Methods 17, 509-513. doi: 10.1038/ s41592-020-0817-9

Knowles, J. K., Rajadas, J., Nguyen, T. V., Yang, T., Lemieux, M. C., Vander Griend, L., et al. (2009). The p75 neurotrophin receptor promotes amyloid-beta(1-42)induced neuritic dystrophy in vitro and in vivo. J. Neurosci. 29, 10627-10637. doi: 10.1523/jneurosci.0620-09.2009

Komiyama, T., Sato, T. R., O'connor, D. H., Zhang, Y. X., Huber, D., Hooks, B. M., et al. (2010). Learning-related fine-scale specificity imaged in motor cortex circuits of behaving mice. Nature 464, 1182-1186. doi: 10.1038/nature08897

Lauterbach, M. A., Ronzitti, E., Sternberg, J. R., Wyart, C., and Emiliani, V. (2015). Fast calcium imaging with optical sectioning via HiLo microscopy. PLoS ONE 10:e0143681. doi: 10.1371/journal.pone.0143681

Lechasseur, Y., Dufour, S., Lavertu, G., Bories, C., Deschenes, M., Vallee, R., et al. (2011). A microprobe for parallel optical and electrical recordings from single neurons in vivo. Nat. Methods 8, 319-325. doi: 10.1038/nmeth.1572

Lee, S. A., Holly, K. S., Voziyanov, V., Villalba, S. L., Tong, R., Grigsby, H. E., et al. (2016). Gradient index microlens implanted in prefrontal cortex of mouse does not affect behavioral test performance over time. PLOS ONE 11:e0146533. doi: 10.1371/journal.pone.0146533

Levene, M. J., Dombeck, D. A., Kasischke, K. A., Molloy, R. P., and Webb, W. W. (2004). In vivo multiphoton microscopy of deep brain tissue. J. Neurophysiol. 91, 1908-1912. doi: 10.1152/jn.01007.2003

Liberti, W. A., Perkins, L. N., Leman, D. P., and Gardner, T. J. (2017). An open source, wireless capable miniature microscope system. J. Neural Eng. 14:045001. doi: 10.1088/1741-2552/aa6806

Lim, D., Ford, T. N., Chu, K. K., and Mertz, J. (2011). Optically sectioned in vivo imaging with speckle illumination HiLo microscopy. J. Biomed. Opt. 16:016014. doi: $10.1117 / 1.3528656$

Lin, M. Z., and Schnitzer, M. J. (2016). Genetically encoded indicators of neuronal activity. Nat. Neurosci. 19, 1142-1153. doi: 10.1038/nn.4359

Logothetis, N., Merkle, H., Augath, M., Trinath, T., and Ugurbil, K. (2002). Ultra high-resolution fMRI in monkeys with implanted RF coils. Neuron 35, 227-242. doi: $10.1016 /$ s0896-6273(02)00775-4 
Lovett-Barron, M., Kaifosh, P., Kheirbek, M. A., Danielson, N., Zaremba, J. D., and Reardon, T. R. (2014). Dendritic inhibition in the hippocampus supports fear learning. Science 343, 857-863. doi: 10.1126/science.1247485

Malvaut, S., Gribaudo, S., Hardy, D., David, L. S., Daroles, L., Labrecque, S., et al. (2017). CaMKIIalpha expression defines two functionally distinct populations of granule cells involved in different types of odor behavior. Curr. Biol. 27:e3316.

Miller, J. E., Ayzenshtat, I., Carrillo-Reid, L., and Yuste, R. (2014). Visual stimuli recruit intrinsically generated cortical ensembles. Proc. Natl. Acad. Sci. U.S.A. 111, E4053-E4061.

Moore, J. J., Ravassard, P. M., Ho, D., Acharya, L., Kees, A. L., Vuong, C., et al. (2017). Dynamics of cortical dendritic membrane potential and spikes in freely behaving rats. Science 355:eaaj1497. doi: 10.1126/science.aaj1497

Morris, R. (1984). Developments of a water-maze procedure for studying spatial learning in the rat. J. Neurosci. Methods 11, 47-60. doi: 10.1016/0165-0270(84) 90007-4

Nadler, J. J., Moy, S. S., Dold, G., Trang, D., Simmons, N., Perez, A., et al. (2004). Automated apparatus for quantitation of social approach behaviors in mice. Genes Brain Behav. 3, 303-314. doi: 10.1111/j.1601-183x.2004.00071.x

Nestler, E. J., and Hyman, S. E. (2010). Animal models of neuropsychiatric disorders. Nat. Neurosci. 13, 1161-1169.

Nguyen, J. P., Shipley, F. B., Linder, A. N., Plummer, G. S., Liu, M., Setru, S. U., et al. (2016). Whole-brain calcium imaging with cellular resolution in freely behaving Caenorhabditis elegans. Proc. Natl. Acad. Sci. U.S.A. 113, E1074-E1081.

Nicolelis, M. A., and Ribeiro, S. (2002). Multielectrode recordings: the next steps. Curr. Opin. Neurobiol. 12, 602-606. doi: 10.1016/s0959-4388(02)00374-4

Niell, C. M., and Stryker, M. P. (2010). Modulation of visual responses by behavioral state in mouse visual cortex. Neuron 65, 472-479. doi: 10.1016/j. neuron.2010.01.033

Nimmerjahn, A., Mukamel, E. A., and Schnitzer, M. J. (2009). Motor behavior activates Bergmann glial networks. Neuron 62, 400-412. doi: 10.1016/j.neuron. 2009.03.019

Nobauer, T., Skocek, O., Pernia-Andrade, A. J., Weilguny, L., Traub, F. M., Molodtsov, M. I., et al. (2017). Video rate volumetric $\mathrm{Ca}(2+)$ imaging across cortex using seeded iterative demixing (SID) microscopy. Nat. Methods 14, 811-818. doi: 10.1038/nmeth.4341

Obernier, K., and Alvarez-Buylla, A. (2019). Neural stem cells: origin, heterogeneity and regulation in the adult mammalian brain. Development 146:dev156059. doi: $10.1242 /$ dev.156059

O'connor, D. H., Peron, S. P., Huber, D., and Svoboda, K. (2010). Neural activity in barrel cortex underlying vibrissa-based object localization in mice. Neuron 67 , 1048-1061. doi: 10.1016/j.neuron.2010.08.026

O'keefe, J., and Dostrovsky, J. (1971). The hippocampus as a spatial map. Preliminary evidence from unit activity in the freely-moving rat. Brain Res. 34, 171-175. doi: 10.1016/0006-8993(71)90358-1

Ozbay, B. N., Futia, G. L., Ma, M., Bright, V. M., Gopinath, J. T., Hughes, E. G., et al. (2018). Three dimensional two-photon brain imaging in freely moving mice using a miniature fiber coupled microscope with active axial-scanning. Sci. Rep. 8:8108.

Ozbay, B. N., Losacco, J. T., Cormack, R., Weir, R., Bright, V. M., Gopinath, J. T., et al. (2015). Miniaturized fiber-coupled confocal fluorescence microscope with an electrowetting variable focus lens using no moving parts. Opt. Lett. 40, 2553-2556.

Patel, J. M., Swanson, J., Ung, K., Herman, A., Hanson, E., Ortiz-Guzman, J., et al. (2019). Sensory perception drives food avoidance through excitatory basal forebrain circuits. Elife 8:e44548.

Patterson, M. A., Lagier, S., and Carleton, A. (2013). Odor representations in the olfactory bulb evolve after the first breath and persist as an odor afterimage. Proc. Natl. Acad. Sci. U.S.A. 110, E3340-E3349.

Petreanu, L., Gutnisky, D. A., Huber, D., Xu, N. L., O'connor, D. H., Tian, L., et al. (2012). Activity in motor-sensory projections reveals distributed coding in somatosensation. Nature 489, 299-303. doi: 10.1038/nature11321

Pilz, G. A., Bottes, S., Betizeau, M., Jorg, D. J., Carta, S., Simons, B. D., et al. (2018). Live imaging of neurogenesis in the adult mouse hippocampus. Science 359, 658-662. doi: 10.1126/science.aao5056

Piyawattanametha, W., Barretto, R. P., Ko, T. H., Flusberg, B. A., Cocker, E. D., $\mathrm{Ra}, \mathrm{H}$., et al. (2006). Fast-scanning two-photon fluorescence imaging based on a microelectromechanical systems two- dimensional scanning mirror. Opt. Lett. 31, 2018-2020.
Qian, Y., Piatkevich, K. D., Mc Larney, B., Abdelfattah, A. S., Mehta, S., Murdock, M. H., et al. (2019). A genetically encoded near-infrared fluorescent calcium ion indicator. Nat. Methods 16, 171-174.

Resendez, S. L., Jennings, J. H., Ung, R. L., Namboodiri, V. M., Zhou, Z. C., Otis, J. M., et al. (2016). Visualization of cortical, subcortical and deep brain neural circuit dynamics during naturalistic mammalian behavior with head-mounted microscopes and chronically implanted lenses. Nat. Protoc. 11, 566-597. doi: 10.1038/nprot.2016.021

Rowland, D. C., Obenhaus, H. A., Skytoen, E. R., Zhang, Q., Kentros, C. G., Moser, E. I., et al. (2018). Functional properties of stellate cells in medial entorhinal cortex layer II. Elife 7:e36664.

Sawinski, J., Wallace, D. J., Greenberg, D. S., Grossmann, S., Denk, W., and Kerr, J. N. (2009). Visually evoked activity in cortical cells imaged in freely moving animals. Proc. Natl. Acad. Sci. U.S.A. 106, 19557-19562. doi: 10.1073/pnas. 0903680106

Sekiguchi, K. J., Shekhtmeyster, P., Merten, K., Arena, A., Cook, D., Hoffman, E., et al. (2016). Imaging large-scale cellular activity in spinal cord of freely behaving mice. Nat. Commun. 7:11450.

Senarathna, J., Yu, H., Deng, C., Zou, A. L., Issa, J. B., Hadjiabadi, D. H., et al. (2019). A miniature multi-contrast microscope for functional imaging in freely behaving animals. Nat. Commun. 10:99.

Sheffield, M. E., and Dombeck, D. A. (2015). Calcium transient prevalence across the dendritic arbour predicts place field properties. Nature 517, 200-204. doi: 10.1038/nature13871

Shen, J., Wang, D., Wang, X., Gupta, S., Ayloo, B., Wu, S., et al. (2019). Neurovascular coupling in the dentate gyrus regulates adult hippocampal neurogenesis. Neuron 103:e873.

Shen, Y., Nasu, Y., Shkolnikov, I., Kim, A., and Campbell, R. E. (2020). Engineering genetically encoded fluorescent indicators for imaging of neuronal activity: progress and prospects. Neurosci. Res. 152, 3-14. doi: 10.1016/j.neures.2020. 01.011

Shin, G., Gomez, A. M., Al-Hasani, R., Jeong, Y. R., Kim, J., Xie, Z., et al. (2017). Flexible near-field wireless optoelectronics as subdermal implants for broad applications in optogenetics. Neuron 93, 509-521.e503.

Shoham, D., Glaser, D. E., Arieli, A., Kenet, T., Wijnbergen, C., Toledo, Y., et al. (1999). Imaging cortical dynamics at high spatial and temporal resolution with novel blue voltage-sensitive dyes. Neuron 24, 791-802. doi: 10.1016/s08966273(00)81027-2

Shoham, S., O'connor, D. H., and Segev, R. (2006). How silent is the brain: is there a "dark matter" problem in neuroscience? J. Compar. Physiol. A Neuroethol. Sens. Neural Behav. Physiol. 192, 777-784. doi: 10.1007/s00359-006-0117-6

Shuman, T., Aharoni, D., Cai, D. J., Lee, C. R., Chavlis, S., Page-Harley, L., et al. (2020). Breakdown of spatial coding and interneuron synchronization in epileptic mice. Nat. Neurosci. 23, 229-238. doi: 10.1038/s41593-019-0559-0

Skocek, O., Nobauer, T., Weilguny, L., Martinez Traub, F., Xia, C. N., Molodtsov, M. I., et al. (2018). High-speed volumetric imaging of neuronal activity in freely moving rodents. Nat. Methods 15, 429-432. doi: 10.1038/s41592-018-0008-0

Stamatakis, A. M., Schachter, M. J., Gulati, S., Zitelli, K. T., Malanowski, S., Tajik, A., et al. (2018). Simultaneous optogenetics and cellular resolution calcium imaging during active behavior using a miniaturized microscope. Front. Neurosci. 12:496. doi: 10.3389/fnins.2018.00496

Stensola, H., Stensola, T., Solstad, T., Froland, K., Moser, M. B., and Moser, E. I. (2012). The entorhinal grid map is discretized. Nature 492, 72-78. doi: 10.1038/ nature11649

Sterniczuk, R., Antle, M. C., Laferla, F. M., and Dyck, R. H. (2010). Characterization of the $3 \mathrm{xTg}-\mathrm{AD}$ mouse model of Alzheimer's disease: part 2. Behavioral and cognitive changes. Brain Res. 1348, 149-155. doi: 10.1016/j.brainres.2010.06.011

Thurley, K., and Ayaz, A. (2017). Virtual reality systems for rodents. Curr. Zool. 63, 109-119. doi: 10.1093/cz/zow070

Tian, L., Hires, S. A., and Looger, L. L. (2012). Imaging neuronal activity with genetically encoded calcium indicators. Cold Spring Harb Protoc. 2012, 647-656.

Tian, L., Hires, S. A., Mao, T., Huber, D., Chiappe, M. E., Chalasani, S. H., et al. (2009). Imaging neural activity in worms, flies and mice with improved GCaMP calcium indicators. Nat. Methods 6, 875-881. doi: 10.1038/nmeth.1398

Torper, O., and Gotz, M. (2017). Brain repair from intrinsic cell sources: turning reactive glia into neurons. Prog. Brain Res. 230, 69-97. doi: 10.1016/bs.pbr.2016. 12.010 
Trainito, C., Von Nicolai, C., Miller, E. K., and Siegel, M. (2019). Extracellular spike waveform dissociates four functionally distinct cell classes in primate cortex. Curr Biol 29, 2973-2982.e2975.

Turner, J. N., Shain, W., Szarowski, D. H., Andersen, M., Martins, S., Isaacson, M., et al. (1999). Cerebral astrocyte response to micromachined silicon implants. Exp. Neurol. 156, 33-49. doi: 10.1006/exnr.1998.6983

Verhagen, J. V., Wesson, D. W., Netoff, T. I., White, J. A., and Wachowiak, M. (2007). Sniffing controls an adaptive filter of sensory input to the olfactory bulb. Nat. Neurosci. 10, 631-639. doi: 10.1038/nn1892

Vicidomini, C., Guo, N., and Sahay, A. (2020). Communication, cross talk, and signal integration in the adult hippocampal neurogenic niche. Neuron 105, 220-235. doi: 10.1016/j.neuron.2019.11.029

Wallace, J., Lord, J., Dissing-Olesen, L., Stevens, B., and Murthy, V. N. (2020). Microglial depletion disrupts normal functional development of adult-born neurons in the olfactory bulb. Elife 9, e50531.

Wang, C., and Ji, N. (2012). Pupil-segmentation-based adaptive optical correction of a high-numerical-aperture gradient refractive index lens for two-photon fluorescence endoscopy. Opt. Lett. 37, 2001-2003.

Wang, J., Shen, J., Kirschen, G. W., Gu, Y., Jessberger, S., and Ge, S. (2019). Lateral dispersion is required for circuit integration of newly generated dentate granule cells. Nat. Commun. 10:3324.

Wilson, M. A., and Mcnaughton, B. L. (1993). Dynamics of the hippocampal ensemble code for space. Science 261, 1055-1058. doi: 10.1126/science.8351520

Xu, N. L., Harnett, M. T., Williams, S. R., Huber, D., O'connor, D. H., Svoboda, K., et al. (2012). Nonlinear dendritic integration of sensory and motor input during an active sensing task. Nature 492, 247-251. doi: 10.1038/nature11601

Yashiro, H., Nakahara, I., Funabiki, K., and Riquimaroux, H. (2017). Microendoscopic system for functional assessment of neural circuits in deep brain regions: simultaneous optical and electrical recordings of auditory responses in mouse's inferior colliculus. Neurosci. Res. 119, 61-69. doi: 10.1016/j.neures. 2017.01.002

Youmans, K. L., Tai, L. M., Nwabuisi-Heath, E., Jungbauer, L., Kanekiyo, T., and Gan, M. (2012). APOE4-specific changes in Abeta accumulation in a new transgenic mouse model of Alzheimer disease. J. Biol. Chem. 287, 41774-41786. doi: 10.1074/jbc.m112.407957

Ziv, Y., and Ghosh, K. K. (2015). Miniature microscopes for large-scale imaging of neuronal activity in freely behaving rodents. Curr. Opin. Neurobiol. 32, 141-147. doi: 10.1016/j.conb.2015.04.001

Zong, W., Wu, R., Li, M., Hu, Y., Li, Y., Li, J., et al. (2017). Fast high-resolution miniature two-photon microscopy for brain imaging in freely behaving mice. Nat. Methods 14, 713-719. doi: 10.1038/nmeth.4305

Zou, Y., Zhang, W., Chau, F. S., and Zhou, G. (2015). Miniature adjustable-focus endoscope with a solid electrically tunable lens. Opt. Express 23, 20582-20592.

Conflict of Interest: SD and HD declare a conflict of interest. SD is the owner of Doric Lenses and HD is an R\&D scientist at Doric Lenses.

The remaining authors declare that the research was conducted in the absence of any commercial or financial relationships that could be construed as a potential conflict of interest.

Copyright (c) 2020 Malvaut, Constantinescu, Dehez, Doric and Saghatelyan. This is an open-access article distributed under the terms of the Creative Commons Attribution License (CC BY). The use, distribution or reproduction in other forums is permitted, provided the original author(s) and the copyright owner(s) are credited and that the original publication in this journal is cited, in accordance with accepted academic practice. No use, distribution or reproduction is permitted which does not comply with these terms. 